\title{
Effect of Suction on the Drained Seismic Compression of Unsaturated Sand
}

\author{
Wenyong Rong, ${ }^{1, *}$ and John S. McCartney ${ }^{1}$ \\ ${ }^{1}$ University of California San Diego, Department of Structural Engineering, 92093-0085, USA
}

\begin{abstract}
Backfill soils in many geotechnical applications are compacted and are likely to be in an unsaturated state during operation. In earthquake-prone areas, seismic compression of unsaturated backfill soils should be understood as small settlements may have significant impacts on the performance of overlying infrastructure like bridge decks, roadways, or railways. Accordingly, the goal of this paper is to describe the results from a series of constant suction, drained, cyclic simple shear tests on unsaturated sands subjected to a range of shear strain amplitudes. A new cyclic simple shear apparatus was developed that involves control of the matric suction and monitoring of changes in degree of saturation using the hanging column approach along with monitoring of the matric suction using an embedded tensiometer.
\end{abstract}

\section{Introduction}

Seismic compression is defined as the accrual of contractive volumetric strains in soils when subjected to earthquake shaking or cyclic loading and has been recognized as an important cause of seismically-induced damage to buildings and geotechnical structures. The state-of-the-practice method used to predict seismic compression during earthquakes consists of a simplified procedure developed by Tokimatsu and Seed [1], which is based on laboratory cyclic simple shear test results for saturated and dry quartz sands reported by Silver and Seed [2]. However, many natural soil layers near the ground surface are above the water table and may be unsaturated. Further, many compacted soil layers in retaining walls and slopes may also be designed with the intention of remaining in unsaturated conditions. Accurately evaluate seismically induced settlement in these geo-structures might be a substantial design factor, where small settlements may have a significant effect. In recent years, experimental advancements have been carried out on the dependence of soil dynamic properties and seismic compression on the matric suction or the degree of saturation. The air in the pores of unsaturated soils along with the contribution of matric suction to interparticle forces may affect their dynamic properties $([3,4])$. Whang et al. [5] found that the degree of saturation was important for soils with moderately plastic fines, but relatively unimportant for soils with low-plasticity fines. Sawada et al. [6] found significant volume change could occur during undrained cyclic triaxial shearing primarily due to the compressibility of pore air in unsaturated sands, but volume changes were almost identical under different initial degrees of saturation if considering the postliquefaction drainage. Unno et al. [7] performed undrained cyclic triaxial tests on unsaturated sands and found that initial degree of saturation affects the volume change of unsaturated sands along with the magnitude of changes in pore air and pore water pressure. It should be noted that most of the unsaturated specimens were achieved by tamping and kneading wet soils to target relative densities which may have led to uncertainties associated with compaction-induced soil structure. Le and Ghayoomi [8] used a modified cyclic simple shear device to investigate the effect of degree of saturation or matric suction on the seismic compression of F-75 Ottawa sand, and found that unsaturated specimens compressed less than dry or saturated specimens. However, the strain amplitude in their study only reaches $0.06 \%$, the effect of matric suction or degree of saturation on seismic compression of unsaturated sands under larger strain amplitude is not clear.

Although a predictive methodology has been proposed to predict seismic compression of unsaturated soils by Ghayoomi et al. [9], many of the components of this methodology are empirical and require more experimental evidence to use in practice. As seismic compression is a large-strain phenomenon in the field, further research is needed to evaluate the effect of matric suction or degree of saturation on the seismic compression of unsaturated sands subjected to medium to large shear strains in a suction-controlled cyclic simple shear test apparatus. The test results shown in this study may help better understand the mechanisms in the seismic compression behaviour of unsaturated sands when subjected to medium to large strains in fully drained condition and could be used to calibrate constitutive models as well.

\section{Test Material}

The sand investigated in this study is classified a well-graded sand (SW) according to the Unified Soil

\footnotetext{
* Corresponding author: w1rong@eng.ucsd.edu
} 
Classification System (USCS). The particle size distribution curve is shown in Figure 1. The sand has a coefficient of uniformity $\mathrm{C}_{\mathrm{u}}=6.1$, and a coefficient of curvature $C_{c}=1.0$. The specific gravity is 2.61 , and the maximum and minimum void ratios are 0.853 and 0.371 , respectively. A summary of the basic geotechnical properties of the SW sand is presented in Table 1.

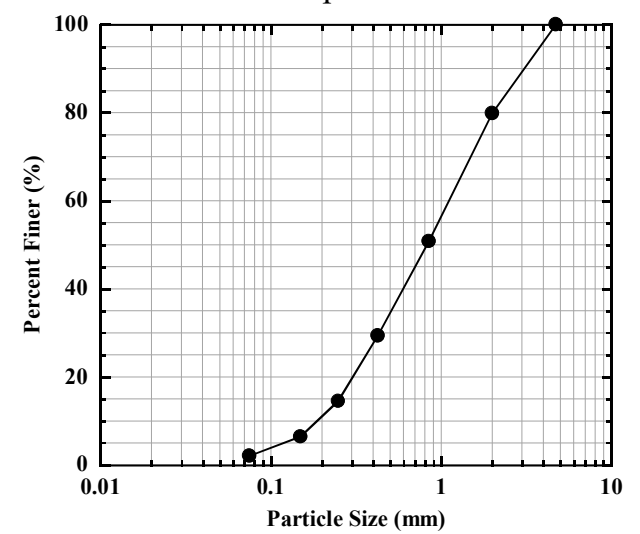

Fig. 1. Particle size distribution curve of the SW sand

Table 1. Summary of the basic properties of the SW sand

\begin{tabular}{lc}
\hline Parameter & Value \\
\hline Specific gravity, $\mathrm{G}_{\mathrm{s}}$ & 2.61 \\
Relative density, $\mathrm{D}_{\mathrm{r}}$ & 0.45 \\
Effective grain size, $\mathrm{D}_{10}(\mathrm{~mm})$ & 0.20 \\
Mean grain size, $\mathrm{D}_{50}(\mathrm{~mm})$ & 0.80 \\
Coefficient of curvature, $\mathrm{C}_{\mathrm{c}}$ & 1.00 \\
Coefficient of uniformity, $\mathrm{C}_{\mathrm{u}}$ & 6.10 \\
Maximum void ratio, $\mathrm{e}_{\max }$ & 0.853 \\
Minimum void ratio, $\mathrm{e}_{\min }$ & 0.371 \\
van Genuchten parameter, $\alpha_{\mathrm{vG}}\left(\mathrm{kPa}^{-1}\right)$ & 0.70 \\
van Genuchten parameter, $\mathrm{N}_{\mathrm{vG}}$ & 2.10 \\
Saturated volumetric water content, $\theta_{\mathrm{s}}$ & 0.39 \\
Residual volumetric water content, $\theta_{\mathrm{r}}$ & 0 \\
\hline
\end{tabular}

A hanging column device was used to measure the soil-water retention curve (SWRC) of the SW sand. A saturated soil specimen was first prepared in the funnel with a fritted ceramic plate (air-entry pressure value of $101.3 \mathrm{kPa}$ ) and then incrementally desaturated by applying negative water pressure $\left(u_{w}\right)$ to the bottom of the specimen while the top of the specimen was left open to the atmosphere (air pressure $u_{a}=0$ ). Once the outflow of water from the bottom boundary was almost identical in a time interval of 30 minutes, the sand specimen was considered to reach hydraulic equilibrium. [10] pointed out that ignoring volume change during SWRC test can lead to peculiar results and major misinterpretation of SWRC. The air-entry pressure value (AEV) of the SW sand at $D_{r}=0.45$ was found to be 1.43 using the proposed method, shown in Figure 2(a). The primary drying and wetting path SWRCs at $\mathrm{D}_{\mathrm{r}}=0.45$ are shown in Figure 2(b), along with the fitted van Genuchten SWRCs.

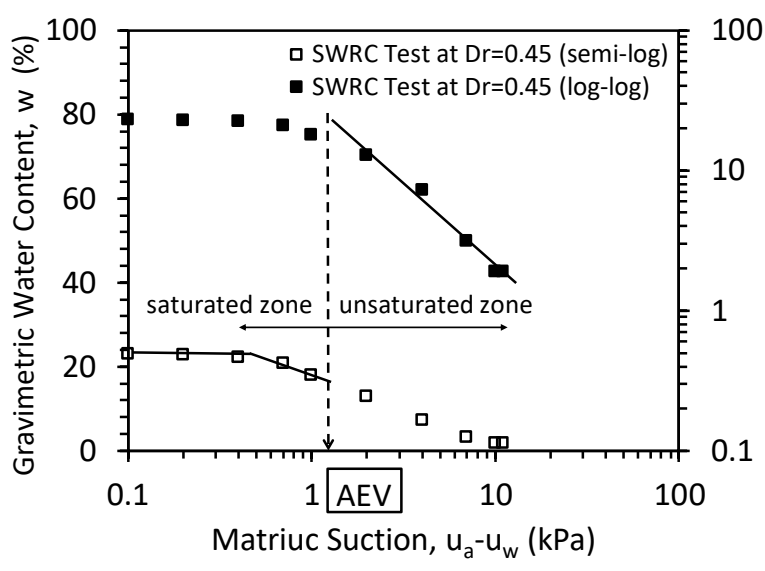

(a)

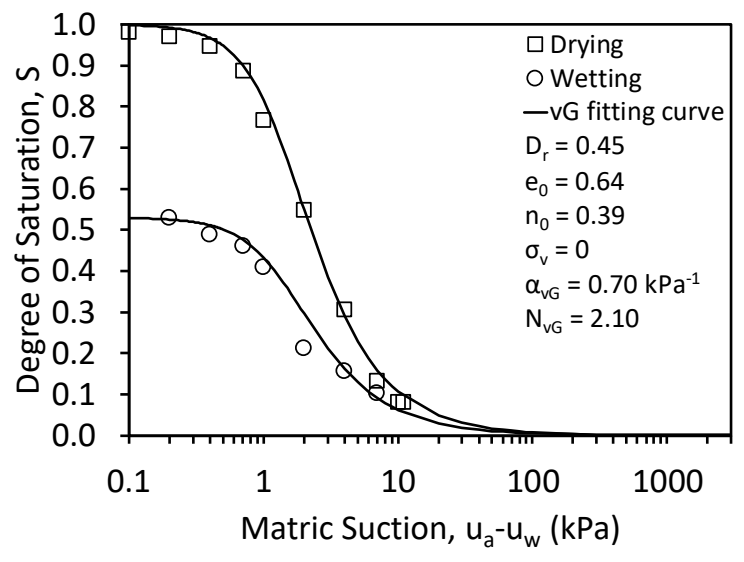

(b)

Fig. 2. (a) Proposed method by Pasha et al. (2015); (b) SWRC for the SW sand at $\mathrm{Dr}=45 \%$.

Using the SWRC for the sand, the initial degree of saturation $\mathrm{S}_{0}$ can be inferred from the initial matric suction $\psi_{0}$. Matric suction is defined as follows:

$$
\psi=u_{a}-u_{w}
$$

The degree of saturation is related to the matric suction through the SWRC, given as follows:

$$
S=\left\{\frac{1}{1+\left[\alpha_{v G} \psi\right]^{N_{v G}}}\right\}^{1-\frac{1}{N_{v G}}}
$$

where $a_{v G}$ and $N_{v G}$ are fitting parameters defined in Table 1 and Figure 2(b).

\section{Apparatus and Specimen Preparation}

To study the effect of suction on the seismic compression of unsaturated sand, a newly-designed specimen housing was carried out to accommodate a ceramic plate with a high air entry pressure as the bottom boundary, which can control the matric suction through a hanging column setup. Further, the bottom platen accommodates a tensiometer that can be inserted into the specimen to monitor changes in matric suction during cyclic shearing. The top platen of the specimen housing is used to provide drainage for air from the specimen and to transmit shear stresses. The cylindrical specimen has a height of $20 \mathrm{~mm}$ and a diameter of $66.7 \mathrm{~mm}$, resulting in a height to 
diameter ratio of $\mathrm{H} / \mathrm{D}=0.3$, which is less than the maximum value of 0.4 set by [11]. A wire-reinforced rubber membrane manufactured by Geonor is used to minimize radial expansion of the specimen during preparation and cyclic shearing but allows free vertical and shear deformation with negligible stiffness from the boundaries. The cross section through the center of the specimen housing along with the attached hanging column setup is shown in Figure 3(a). The specimen on the simple shear device is shown in Figure 3(b).

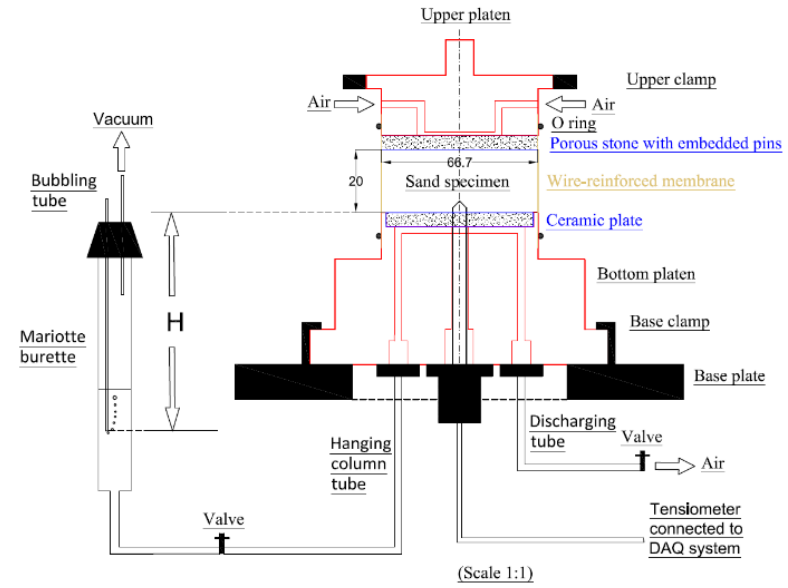

(a)

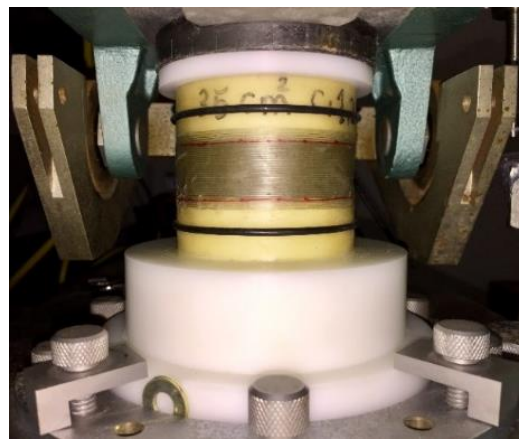

(b)

Fig. 3. (a) Schematic view of the specimen housing;

(b) Specimen housing on the simple shear device.

To prepare unsaturated specimens with different initial suctions, the bottom platen was first fastened on the simple shear device using clamps, then dry pluviation was used to place pre-weighed sand into the chamber surrounded by the rubber membrane to reach the target relative density of $45 \%$. The dry specimen was slowly saturated by de-aired water through the bottom boundary until water was observed to leave the top of the specimen. Upward flow was maintained for several hours to flush out trapped air within the specimen. While monitoring the matric suction in the specimen using the inserted tensiometer, saturated specimens were then desaturated to different target matric suctions using the hanging column approach. Then, vertical stress was applied to the specimen through the top platen.

\section{Testing Program}

Four initial states, marked A, B, C, D in Figure 4, along with the dry and the saturated conditions were chosen to evaluate the suction effect on seismic compression. The initial states of the specimens, like initial matrix suction $\psi_{0}$, initial degree of saturation $\mathrm{S}_{0}$, initial gravimetric water content $\mathrm{w}_{0}$, initial volumetric water content $\theta_{\mathrm{w} 0}$ and applied cyclic shear strain $\gamma$, are presented in Table 2 . The vertical total stress in all the tests was $50 \mathrm{kPa}$, and the strain rate was chosen to be $0.833 \% / \mathrm{min}$ to ensure full drainage of the pore water and the pore air within the specimen so that matric suction and effective stress will not change. Since radial expansion of the specimen is minimized by the wire-reinforced rubber membrane, the volumetric strain, $\varepsilon_{\mathrm{v}}$, during cyclic shearing is assumed to be due to changes in height.

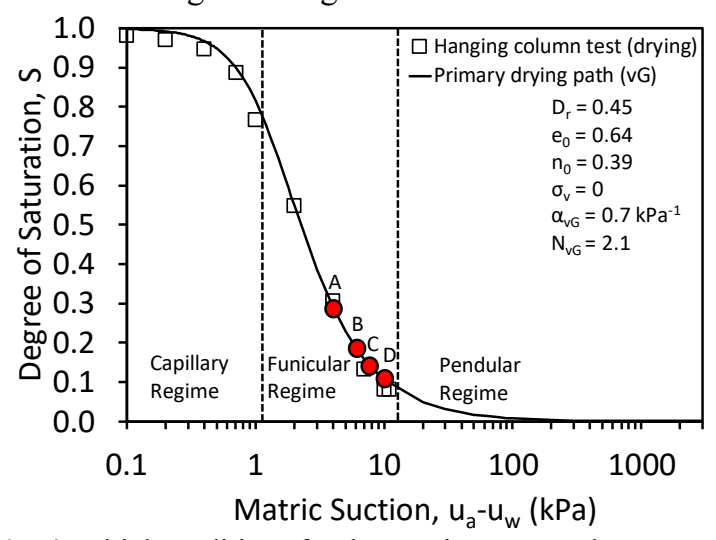

Fig. 4. Initial conditions for the specimens tested

Table 2. Test program

\begin{tabular}{cccccc}
\hline $\begin{array}{c}\text { Specimen } \\
\text { NO. }\end{array}$ & $\begin{array}{c}\psi_{0} \\
(\mathrm{kPa})\end{array}$ & $\mathrm{S}_{0}$ & $\mathrm{w}_{0}$ & $\theta_{\mathrm{w} 0}$ & $\begin{array}{c}\gamma \\
(\%)\end{array}$ \\
\hline $\mathrm{A}-1$ & 3.92 & 0.31 & 0.076 & 0.121 & 0.3 \\
$\mathrm{~A}-2$ & 3.87 & 0.31 & 0.077 & 0.123 & 1 \\
$\mathrm{~A}-3$ & 3.96 & 0.31 & 0.075 & 0.120 & 3 \\
$\mathrm{~A}-4$ & 4.02 & 0.30 & 0.074 & 0.118 & 5 \\
$\mathrm{~B}-1$ & 6.03 & 0.20 & 0.049 & 0.078 & 0.3 \\
$\mathrm{~B}-2$ & 5.93 & 0.20 & 0.050 & 0.079 & 1 \\
$\mathrm{~B}-3$ & 5.95 & 0.20 & 0.050 & 0.079 & 3 \\
$\mathrm{~B}-4$ & 5.88 & 0.21 & 0.050 & 0.080 & 5 \\
$\mathrm{C}-1$ & 8.10 & 0.15 & 0.036 & 0.057 & 0.3 \\
$\mathrm{C}-2$ & 8.01 & 0.15 & 0.036 & 0.058 & 1 \\
$\mathrm{C}-3$ & 7.92 & 0.15 & 0.037 & 0.058 & 3 \\
$\mathrm{C}-4$ & 7.98 & 0.15 & 0.036 & 0.058 & 5 \\
$\mathrm{D}-1$ & 10.12 & 0.12 & 0.028 & 0.045 & 0.3 \\
$\mathrm{D}-2$ & 10.15 & 0.11 & 0.028 & 0.045 & 1 \\
$\mathrm{D}-3$ & 10.03 & 0.12 & 0.028 & 0.045 & 3 \\
$\mathrm{D}-4$ & 9.94 & 0.12 & 0.029 & 0.046 & 5 \\
\hline & & & & &
\end{tabular}

\section{Test Results}

Time series of volumetric strains for the unsaturated specimens with various initial suctions when subjected to different cyclic strains are presented in Figure 5. 


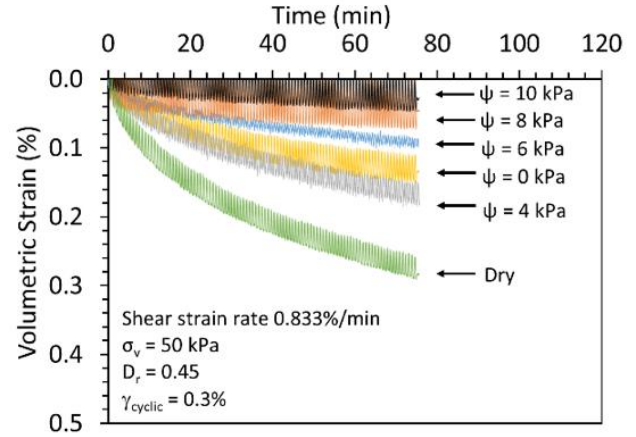

(a)

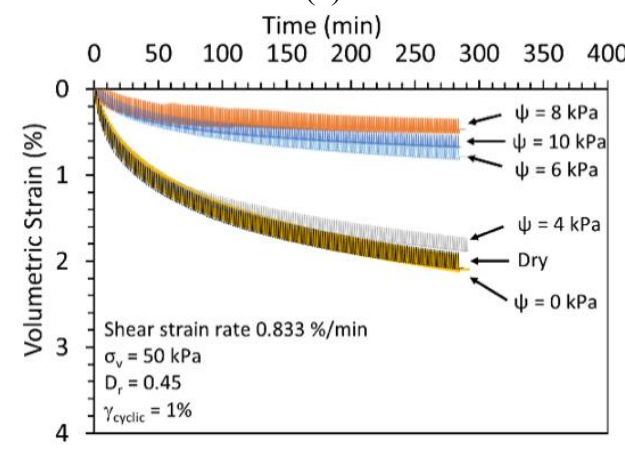

(b)

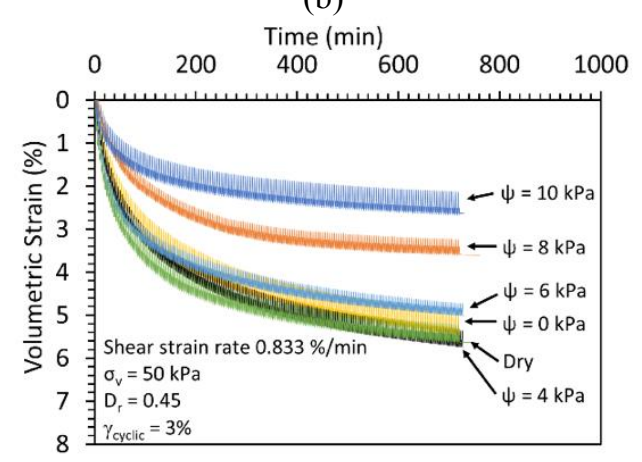

(c)

Time $(\mathrm{min})$ $0 \quad 200 \quad 4006008001000120014001600$

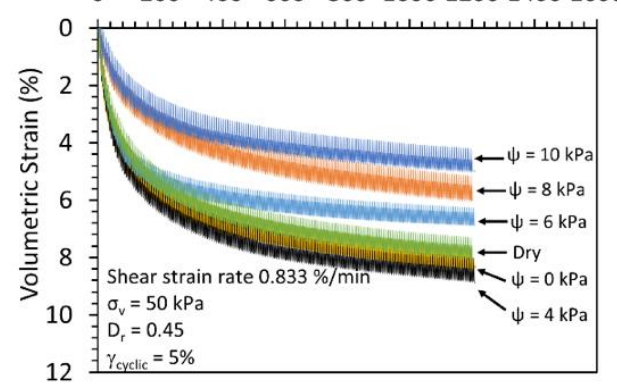

(d)

Fig. 5. Volumetric responses of the unsaturated specimens subjected to various strain amplitudes: (a) $\gamma_{\text {cyclic }}=0.3 \%$; (b) $\gamma_{\text {cyclic }}=1 \%$; (c) $\gamma_{\text {cyclic }}=3 \%$; (d) $\gamma_{\text {cyclic }}=5 \%$

Matric suction has a substantial effect on the volumetric strains of the unsaturated sands especially under larger cyclic strains. Volumetric strains of unsaturated specimens at lower matric suctions (for example, $\psi=4 \mathrm{kPa}$ ) almost double the volumetric strains experienced by specimens with higher matric suctions (for example, $\psi=8 \mathrm{kPa}$ or $10 \mathrm{kPa}$ ). Unsaturated specimens with lower matric suctions experienced almost identical volumetric strains under larger cyclic strains $(\gamma$
$=3 \%$ or $5 \%$ ), but it is not the case under the cyclic strain level of $\gamma=0.3 \%$. Final volumetric strains at number of cycles $\mathrm{N}=200$ are synthesized with strain amplitudes in Figure 6. It can be seen that larger shear strains resulted in larger volumetric contractions for the same suction level, and lower volumetric strains were observed for specimens with higher suctions at the end of shearing. Cyclic Shear Strain (\%)

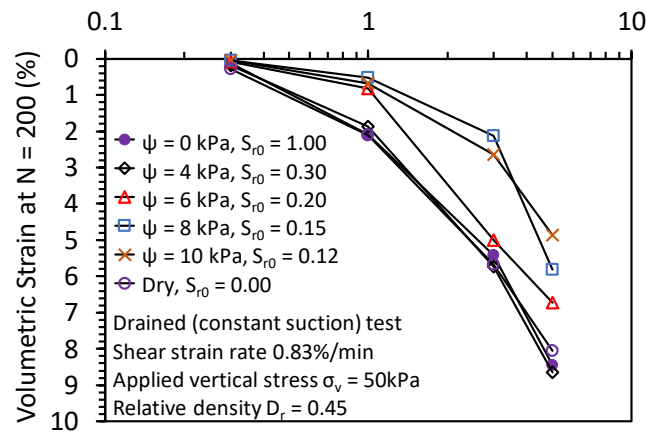

Fig. 6. Volumetric strain at $\mathrm{N}=200$ versus cyclic strain amplitude

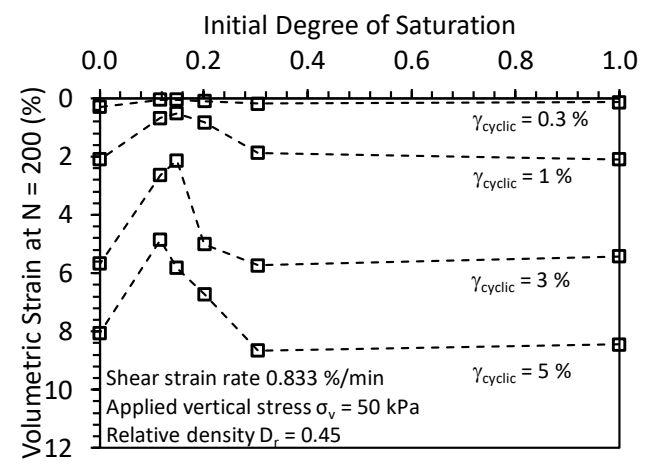

(a)

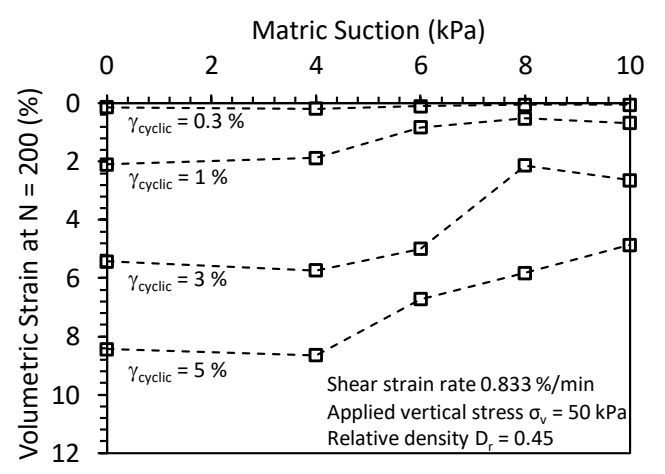

(b)

Fig. 7. The trends in volumetric strain with degree of saturation or suction

Final volumetric strains at $\mathrm{N}=200$ were plotted against initial matric suctions and initial degrees of saturation in Figure 7. For larger cyclic shear strains, specimens with initial degrees of saturation around 0.1 responded in a stiffer manner with lower seismic compression.

\section{Conclusion}

This study used a newly-developed cyclic simple shear device for unsaturated soils to study the effect of matric 
suction on the drained seismic compression of unsaturated sands. The test results indicate that matric suction has a major effect on the seismic compression of the unsaturated specimens. Volumetric strains are smaller for unsaturated specimens with higher suction values than those with lower suctions closer to saturated conditions, especially when subjected to larger cyclic shear strains. Specimens with initial degrees of saturation of approximately 0.1 experience stiffer responses.

\section{References}

1. K. Tokimatsu, H.B. Seed. "Evaluation of settlements in sands due to earthquake shaking." Journal of Geotechnical Engineering. 113(8), 861-878 (1987)

2. M.L. Silver, H.B. Seed. "Deformation characteristics of sands under cyclic loading." Journal of Soil Mechanics and Foundations Div. 97(8), 1081-1098 (1971)

3. A. Khosravi, J.S. McCartney. "Resonant column test for unsaturated soils with suction-saturation control." Geotechnical Testing Journal. 36(6), 1-10 (2011)

4. C.W.W. Ng, J. Xu. "Effects of current suction ratio and recent suction history on small-strain behavior of an unsaturated soil.” Can. Geotech. J. 49(2), 226-243 (2012)

5. D.H. Whang, J.P. Stewart, J.D. Bray. "Effect of compaction conditions on the seismic compression of compacted fill soils." Geotechnical Testing J. 27(4), 1-9 (2004)

6. S. Sawada, Y. Tsukamoto, K. Ishihara. "Residual deformation characteristics of partially saturated sandy soils subjected to seismic excitation." Soil dynamics and earthquake engineering. 26(2-4), 175182 (2006)

7. T. Unno, M. Kazama, R. Uzuoka, N. Sento. "Liquefaction of unsaturated sand considering the pore air pressure and volume compressibility of the soil particle skeleton." Soils and Foundations, 48(1), 87-99 (2008)

8. K.N. Le, M. Ghayoomi. "Cyclic direct simple shear test to measure strain-dependent dynamic properties of unsaturated sand." Geotechnical Testing Journal, 40(3), 381-395 (2017)

9. M. Ghayoomi, J.S. McCartney, H.Y. Ko. "Empirical methodology to estimate seismically induced settlement of partially saturated sand." J. of Geotech. and Geoenv. Eng. 139(3), 367-376 (2012)

10. A.Y. Pasha, A. Khoshghalb, N. Khalili. "Pitfalls in interpretation of gravimetric water content-based soil-water characteristic curve for deformable porous media." Int'l Journal of Geomechanics, 16(6), D4015004 (2015)

11. ASTM D6528-07. "Standard test method for consolidated undrained direct simple shear testing of cohesive soils.” (2007) 